\title{
System for preventing the water cone formation in gas deposits with low gas thickness
}

\author{
D.E. Kopylov, A.V. Strekalov, \\ Industrial University of Tyumen, Tyumen, Russia
}

\begin{abstract}
The article describes the problem of water cone formation in gas deposits of small gas-saturated thickness. The process of pulling the water cone into the production well is analyzed. The most popular and effective methods of solving this problem are presented. A method of using an electric screw pump to prevent water accumulation in the bottomhole zone is proposed. The method of calculating the optimal pump flow rate, which allows operating the well without its overheating, is considered.
\end{abstract}

\section{Introduction}

\subsection{Problem description}

Currently, the main complication in the operation of deposits withlow gas-saturated thickness is the rapid breakthrough of bottom water [1]. In connection with this problem, a water cone begins to move towards the operated well. If the resulting cone of water is not timely eliminated, it will block all perforations, which will lead to the well stopping.

\subsubsection{Relevance of the problem}

We would like to give an example of statistics on wells in the Pyreynoye and Beregovoye fields of PAO Rosneft. It is in these fields where the problem of the bottom water breakthrough is very pronounced. Thus, 19 of the 28 wells at the Pyreynoyefield were stopped due to a high water cut. On the Beregovoye field, the situation is much better:only 8 wells out of 63 were stopped due to a high water cut. This statistic can be seenin Table 1 .

Table 1. Statistics of the operating modes of wells on the Pyreynoye and Beregovoye fields

\begin{tabular}{|c|c|c|c|c|}
\hline $\begin{array}{c}\text { Name of the } \\
\text { field }\end{array}$ & Total wells & $\begin{array}{c}\text { Number of wells } \\
\text { with production } \\
\text { water cut }\end{array}$ & $\begin{array}{c}\text { Operate with } \\
\text { water }\end{array}$ & $\begin{array}{c}\text { Stopped with } \\
\text { water }\end{array}$ \\
\hline Pyreynoye & 28 & 21 & 2 & 19 \\
\hline Beregovoye & 63 & 18 & 10 & 8 \\
\hline
\end{tabular}




\subsubsection{Methods for solving the problem of the bottom water breakthrough}

Currently, not only Russian gas companies but also foreign ones are actively countering this problem. We have already accumulated quite a lot of experience in using various methods to solve the problem of the cone formation:periodic "blowing" of the well; replacement of pump and compressor pipes with pipes of smaller diameter; use of concentric lift and plunger lift systems; use of surfactants with their delivery to the bottom of the well; use of the bottom hole layouts for pumping water.

In this paper, we will consider the last of the listed options for solving the problem, as well as the method for calculating the optimal operation mode of the downhole assembly.

\section{Analysis of the model of water cone formation in gas deposits}

\subsection{Analysis of the dependence of the water rate over time on various values of the permeability anisotropy}

To experiment, the "TNavigator" software for hydrodynamic modeling was used. The simplest reservoir model of the "gas - water" equilibrium system was created. The value of the horizontal permeability was equal to $100 \mathrm{md}$. The vertical permeability varied, and four different values of 10, 25, 50, and $70 \mathrm{md}$ were set. Four calculations were made, where the permeability anisotropy took the values $0.1,0.25,0.5$, and 0.7 . The results of the calculations can be seen in Figure 1.
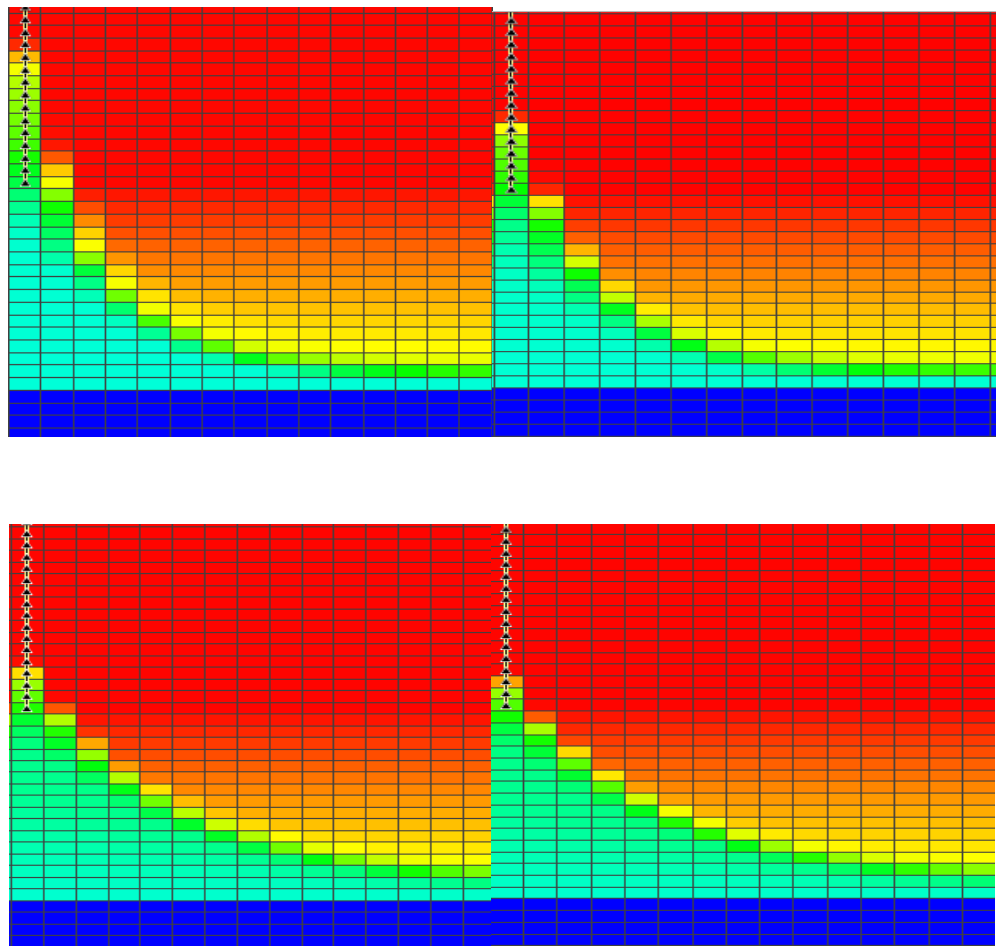

Fig. 1. Distribution of water saturation after 950 days of gas production 
In Figure 1, we observe that when the permeability anisotropy is 0.7 , the water cone is pulled up to 11 of the perforation block. With the lowest permeability anisotropy of 0.1 , the water cone is pulled up to only 3 perforation blocks.

Next, based on the results of the hydrodynamic model, we will graph the dependence of the water rate on time for different values of the permeability anisotropy. It can be seen in Figure 2.

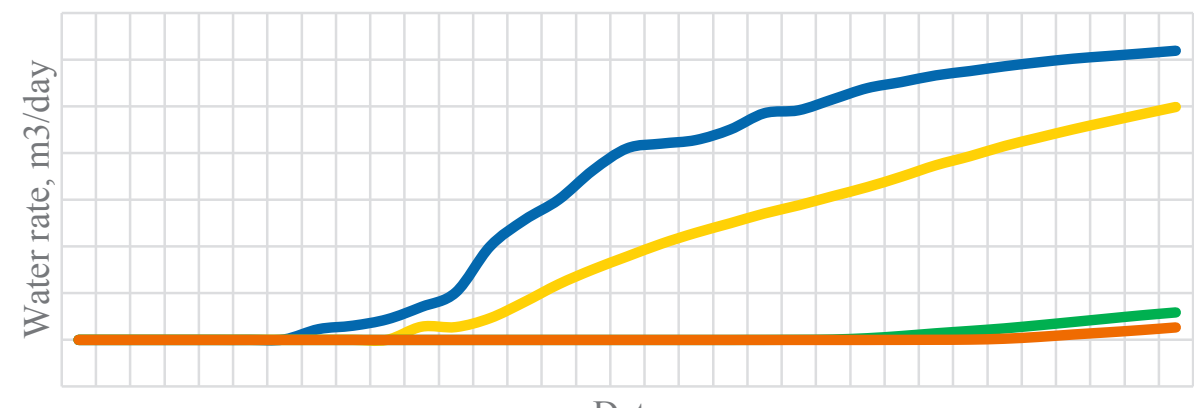

Date

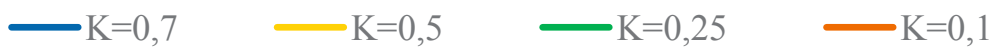

Fig. 2. Graph of the time dependence of water rate for different values of permeability anisotropy

Figure 2 shows that the time of the water breakout and the rateof its movement increase with the increasein permeability anisotropy. The shortest water breakout time and the highest water flow rate with the permeability anisotropy is equal to 0.7 . The longest water breakout time and the lowest water flow rate areachieved in the case with a permeability anisotropy equal to 0.1 .

Based on this study, we can conclude that vertical permeability increases in water production in gas deposits. The higher the vertical permeability, the greater is the flow rate of water from the gas well, hence the larger the volume of the water cone is.

\section{Method to solve the problem of THE water cone formation}

\subsection{Typical assembly of downhole equipment}

Currently, it is very important to remove liquid from the bottom of a gas well. In this paper, we propose to improve and refine the existing promising technology usingan inverted pump $[2,3]$. This technology, as shown by the experience of the Centrilift Company, allows to effectively counter the formation of a water cone in gas fields. In this work, it is proposed to use an electric screw pump instead of a centrifugal one, since the service life of the screw pump is much longer. A typical piece of equipment is shown in Figure 3.

Let us describethe main nodes of this assembly. These are an input module for gas production, a hydro protection module, an electric motor, an input module for pumping reservoir liquid (water) into a water-saturated interval, a check valve, a packer over which the liquid accumulates, and, of course, the pumping unit, i.e., an electric screw pump $[5,6$, 7]. 
Let us pay attention to the operation principle of the entire system. Water that isaccumulated in the above-packer space is forced back into the water-saturated intervalwith an electric screw pump. Since in Western and Eastern Siberia the horizontal permeability is much higher than the vertical one, the system will not accelerate the formation of a water cone, since water will mostly be distributed in the horizontal direction, though it will also move in the vertical direction.

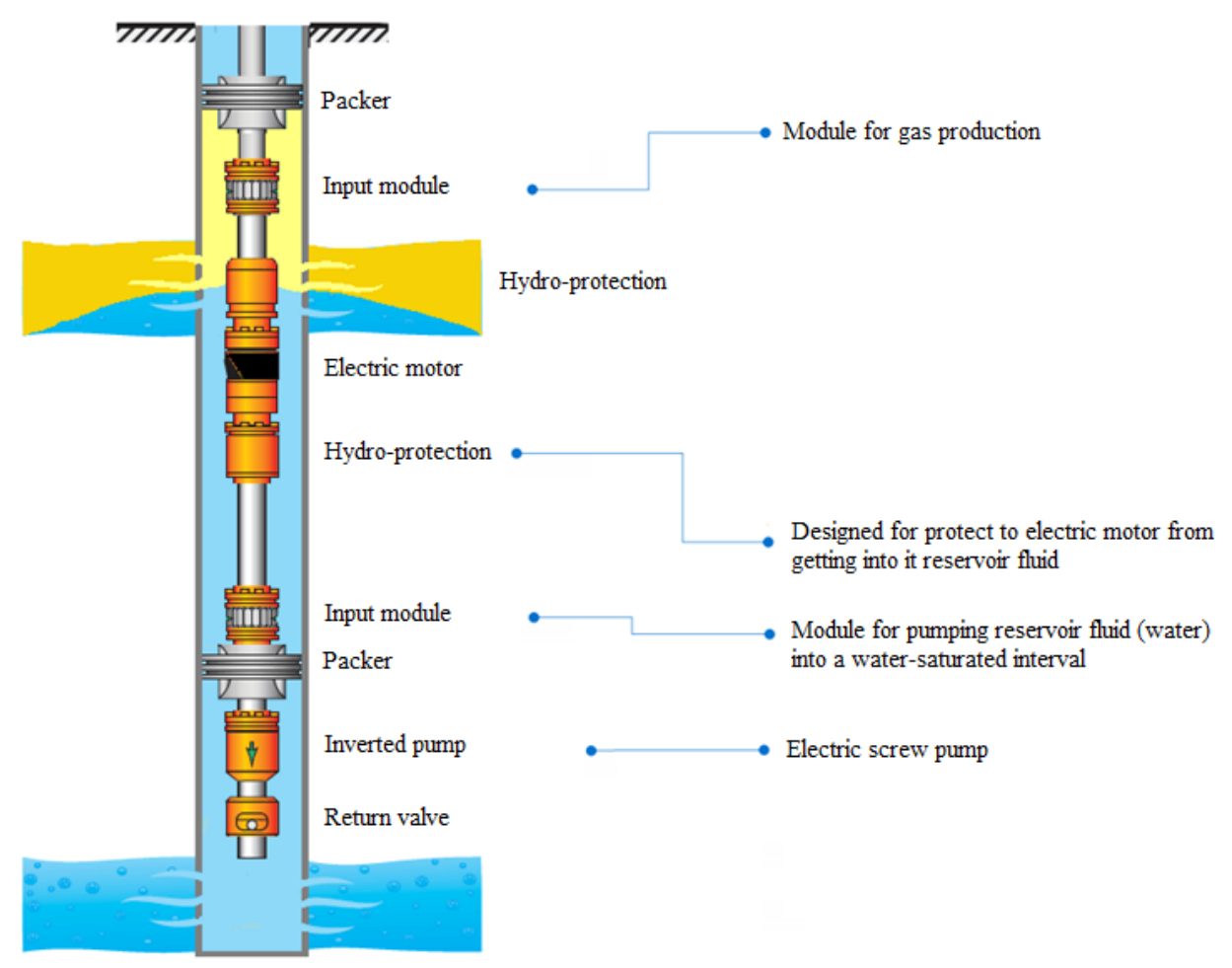

Fig. 3. Typical scheme with electric screw pump of the inverted type

\subsection{Method of selecting the optimal pumping aggregate}

The main element of the entire system is an electric screw pump. For effective operation of the system, it is necessary to determine the optimal performance of the pumping unit undercertain conditions. To do this, atypical scheme (Figure 4) for calculating the optimal pump ratecan be used. 


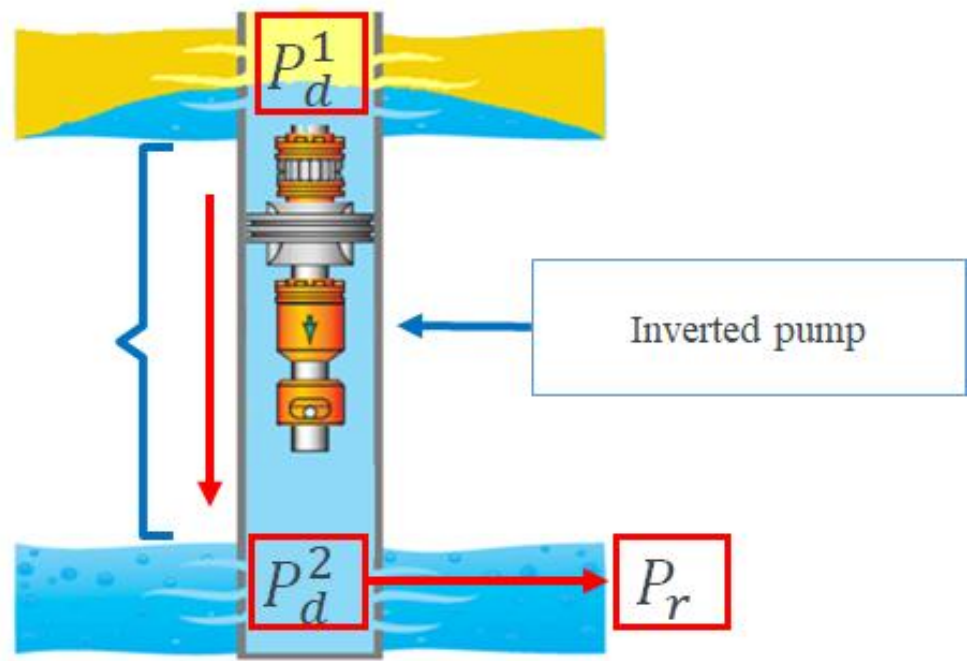

Fig. 4. Scheme of the "layer - well".

Using Figure 4, equation (1)can bederived for the calculation the optimal rate.

$$
\Delta \mathrm{Pesp}(\mathrm{q})-\mathrm{q} / \mathrm{Kp}+\rho \mathrm{g} \Delta \mathrm{h}=\mathrm{P}_{\mathrm{r}}-\mathrm{P}_{\mathrm{d}}{ }^{1}
$$

where $\Delta P \operatorname{esp}(q)=$ pressure characteristic of the pump; $\mathrm{q}=$ optimal rate; $K_{p}=$ productivity factor; $\rho g \Delta h=$ hydrostatic pressure; $P_{r}=$ reservoir pressure; $P_{d}^{1}=$ downhole pressure at the level of the first perforation interval.

The pressure characteristic of the pump is determined by equation (2). The coefficients a, b, c, d arederived from a polynomial of $3^{\text {rd }}$ degree:

$$
\Delta \operatorname{Pesp}(\mathrm{q})=\mathrm{aq}^{3}+\mathrm{bq}^{2}+\mathrm{cq}+\mathrm{d}
$$

The pressure characteristic of the pump is attached tothe screw pump passport. Figure 5 shows the pressure characteristic of the ESP5-100-1000 pump.

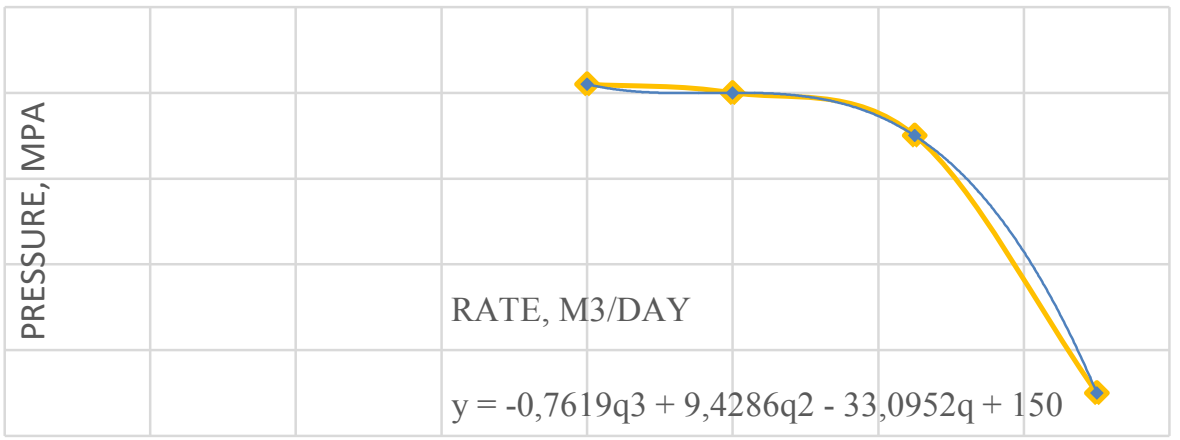

Fig. 5. Pressure characteristic of the pump.

The pressure characteristic of the pumping unit (blue curve) was plotted based on the characteristic points. After that, a polynomial function of $3^{\text {rd }}$ degree was chosen (orange 
curve). For the final calculation of the optimal rate revealing the pressure characteristic of the pumping unit via a polynomial of degree 3 we obtain the final equation (3):

$$
-0,7619 q+9,4286 q^{2}-33,0952 q+150-q / k p+\rho g \Delta h=P_{r}-P_{d}^{1}
$$

The productivity coefficient $k_{p}$ is determined from equation (4)

$$
\mathrm{kp}=2 \pi \mathrm{kh} / \mu_{\mathrm{d}} \ln \mathrm{Re} / \mathrm{r}_{\mathrm{w}}
$$

where $k=$ rock permeability coefficient; $\mathrm{h}=$ capacity of the water-saturated area of the reservoir; $\mu_{d}=$ dynamic viscosity of water; $R_{e}=$ radius of the power loop; $r_{w}=$ radius of the well.

$k, R_{e}, r_{w}$, as well as coefficients a, b, c, and d, were used to select the optimal brand one of the 6 pump brands initially chosen, on the basis of the best result shown. The calculation results for this brand of the pump are shown in Table 2.

Table 2. Results of calculating the optimal supply of the best pumping unit

\begin{tabular}{|c|c|c|c|}
\hline \multicolumn{2}{|c|}{ Brand pump 4 } \\
\hline \multirow{2}{*}{$\begin{array}{c}\text { The radius of the } \\
\text { drainage, } \mathrm{m}\end{array}$} & Permeability,md & Water rate & $\begin{array}{c}\text { In commercial } \\
\text { quantities }\left(\mathrm{m}^{3} / \text { day }\right)\end{array}$ \\
\hline \multirow{3}{*}{500} & 50 & 0.0012 & 108.9500 \\
\cline { 2 - 4 } & $\mathbf{1 5 0}$ & $\mathbf{0 . 0 0 3 7}$ & $\mathbf{3 2 0 . 5 4 8 9}$ \\
\cline { 2 - 4 } & 300 & 0.0074 & 641.1950 \\
\hline
\end{tabular}

Based on the results of calculations, it was concluded that at a permeability of $150 \mathrm{md}$, the pump of brand 4 had the best effThe other brands of pumping units showed efficiencies of 50 and $160 \mathrm{~m}^{3} /$ day.

\section{Analysis of the efficiency of the inverted pump technology}

\subsection{Comparison of possible feed options for pump units}

In the TNavigatorprogram for hydrodynamic modeling, the analysis of production rates was performed when implementing an inverted pump with different feeds $(320,160$ and 50 $\mathrm{m}^{3}$ /day). The results of this analysis are shown in Figure 6 . 


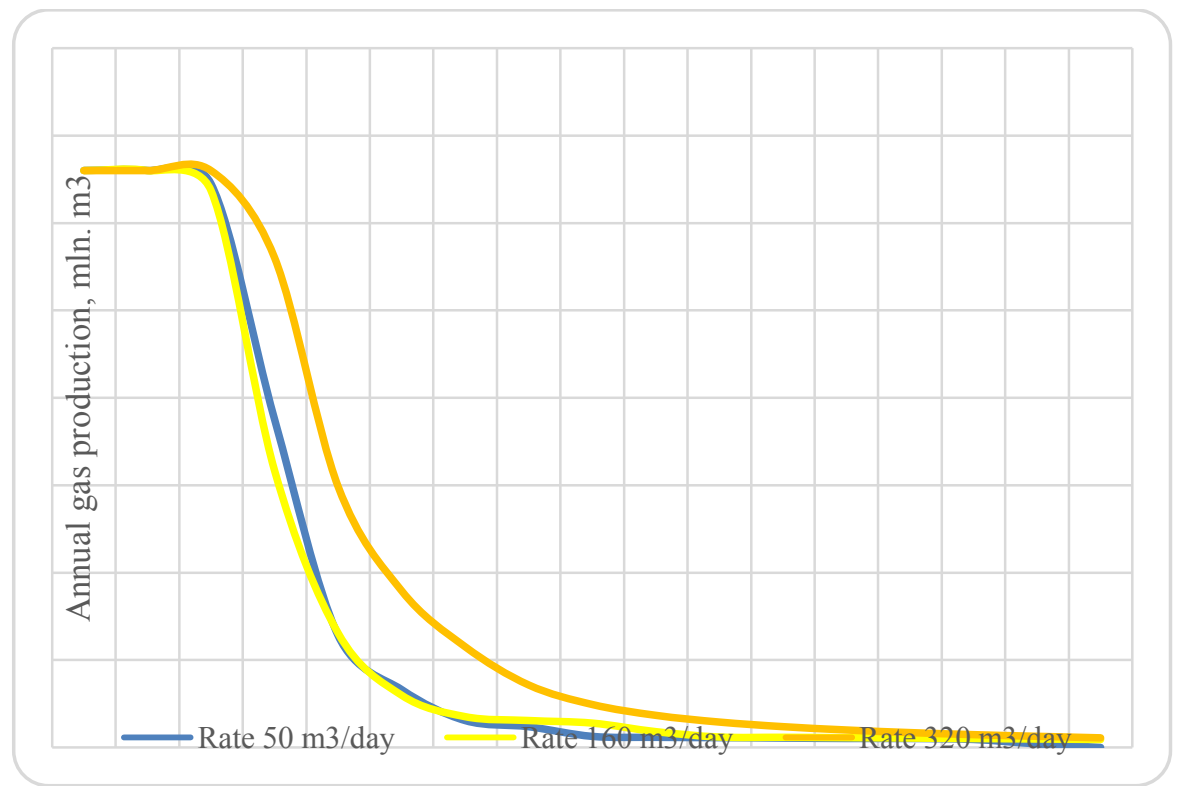

Fig. 6. Comparison of possible pump rate options for one reservoir permeability value

As it can be seen from Figure 6, the best rate is $320 \mathrm{~m}^{3} /$ day. With this rate, there is a noticeable increase in gas production. Rates of 50 and $160 \mathrm{~m}^{3}$ /dayare noticeably inferior in production to the best option.

\subsection{Comparison of gas production without inverted pump (basic option) and with inverted pump at $320 \mathrm{~m}^{3} /$ day}

For this comparison, it was necessary to use the TNavigatorprogram for hydrodynamic modeling ". The results of calculationsfor two options are shown in Figure 7.

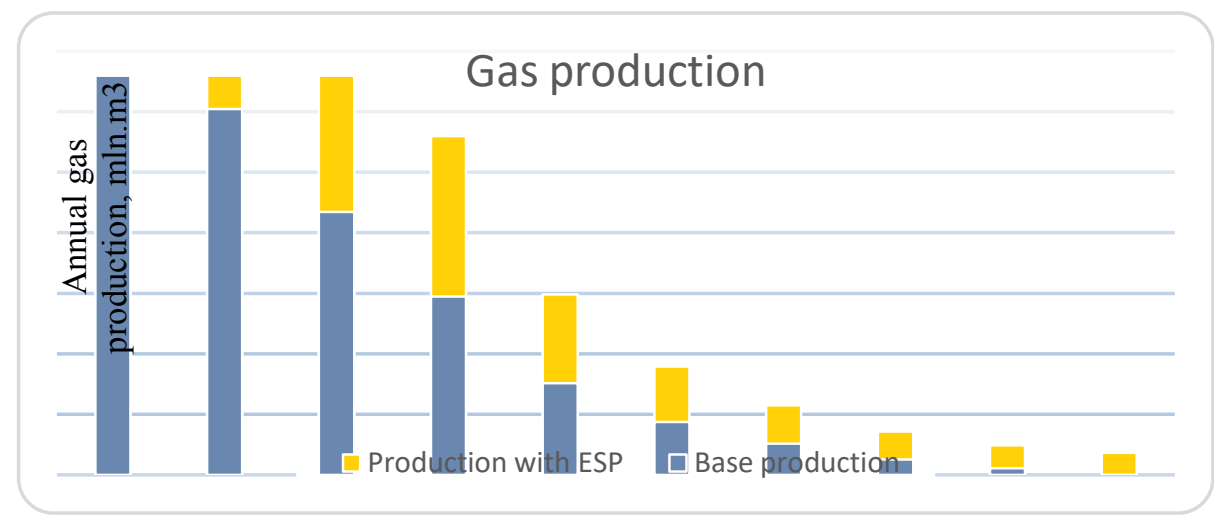

Fig. 7. Diagram of changes in gas production in the basic option and the option with an electric screw pump

Let us note that the beginning of the decline in production without the introduction of the proposed technology occurs in 2 years, and with the introduction of the technology - in 3 years. The duration of the well operation is also increased by more than 3 years. 


\subsection{Analysis of the economic efficiency after the introduction of the technology}

The main criterion for analyzing the effectiveness of the technology implementation was chosen the NPV indicator. The main parameters included in the NPV were theprofit tax of 0.035 rubles $/ \mathrm{m}^{3}$; the cost of gas in the Russian Federation (this cost is routinelyaccepted bycompanies for calculating economic efficiency) of 6 rubles $/ \mathrm{m}^{3}$; the discount rate of 0.15 ; total electricity costs of 402 thousand rubles; lifting of liquid (water) $500 \mathrm{rubles} / \mathrm{m}^{3}$. The results of the NPV analysis are presented in Figure 8.

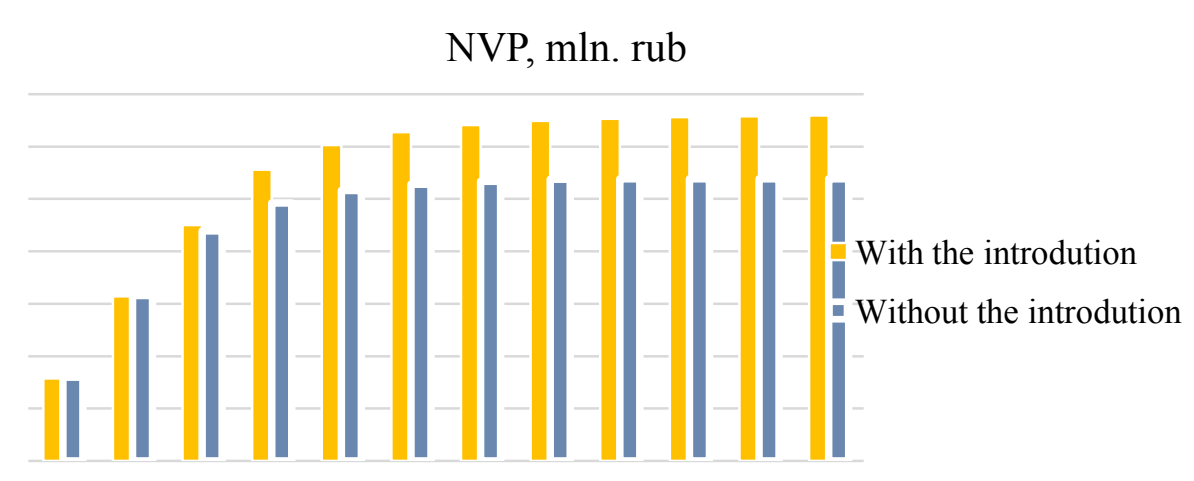

Fig. 8. Diagram of NPV changes in the basic option and the option with an electric screw pump

Figure 8 shows that over 11 years of operation in the version with the introduction of technology there is a noticeable increase in NPV by 602 million rubles.

\section{Conclusions}

\subsection{Automation of pumping unit operation}

To reduce energy costs, it is planned to develop software that will monitor the operation of the pumping unit, the pressure in the well, as well as the volume of accumulated water.

To create the software, studies shallbe performed on the operation of a gas well using an inverted pump in the program for hydrodynamic modeling. After processing the research results, it is necessary to identify correlations of physical dependencies, build graphs of the dependence of the rate of removal of the water cone on the power of the pumping unit, gas flow rate, reservoir productivity coefficient, etc., as well as determine the type of optimizing function.

\subsection{Prospects for the development of technology}

Evaluation of the efficiency of technology showed that the introduction of an inverted electric screw pump is a promising solution. Thanks to the introduction of this technology, it is possible to increase the volume of gas produced, increase the life of the well, as well as NPV. 


\section{References}

1. Sarancha A.V., Sarancha I.S., Mitrofanov D.A., Ovezova S.M. Modern problems of science and education-№1 Technology of production of low-pressure Cenomanian gas $1(2015)$.

2. James L.F., Nickens, H. V. Solving Journal of Petroleum Technology Gas-Well Liquid-Loading Problems 56 (04), 30-36 (2004).

3. James L.F., Nickens H.V. Gulf Professional Publishing Gas well deliquification solutions to gas well liquid loading problems, 314 (2003).

4. Strekalov A.V. Mathematical models of hydraulic systems for controlling reservoir pressure maintenance systems, 15-34 (2007).

5. Nutskova, M. V., Dvounikov, M.V., Kuchin, V.N. Journal of Engineering and Applied Sciences Improving the quality of well completion to limit water inflows 22(12), 59855989 (2017).

6. Panikarovskii E.V., Panikarovskii V.V. Oil and Gas Studies Main causes of stopping gas wells at the final stage of development of deposits 3, 85-89 (2017).

7. Yu-Shu Wu. Multiphase Fluid Flow in Porous and Fractured Reservoir. Colorado School of Mines Golden. CO. USA (2016). 